\title{
Criminologie
}

\section{L’âge et la question criminelle}

\section{Maurice Cusson}

Volume 35, numéro 1, printemps 2002

L'âge et la question criminelle

URI : https://id.erudit.org/iderudit/027510ar

DOI : https://doi.org/10.7202/027510ar

Aller au sommaire du numéro

Éditeur(s)

Les Presses de l'Université de Montréal

ISSN

0316-0041 (imprimé)

1492-1367 (numérique)

Découvrir la revue

Citer ce document

Cusson, M. (2002). L'âge et la question criminelle. Criminologie, 35(1), 3-4. https://doi.org/10.7202/027510ar d'utilisation que vous pouvez consulter en ligne.

https://apropos.erudit.org/fr/usagers/politique-dutilisation/ 


\section{L'âge et la question criminelle}

Maurice Cusson

Professeur

École de criminologie

Université de Montréal

simardgi@crim.umontreal.ca

Donnée fondamentale pour tout être humain, l'âge l'est aussi pour la criminologie. Les petits enfants ne commettent pas de crime, non seulement parce qu'ils ne sont pas pénalement responsables, mais aussi parce qu'ils n'en ont pas la force. Ce sont les adolescents et les jeunes adultes qui fournissent les gros bataillons de l'armée du crime. Avec l'âge mûr, reculent les manifestations les plus voyantes de l'activité délictueuse.

Comme l'amplitude de ces fluctuations est forte, la courbe qui trace les relations entre l'âge et le crime présente des mouvements qui, depuis longtemps, ont frappé les esprits. C'est Quételet qui, le premier, en 1831, a attiré l'attention de la communauté des chercheurs sur l'importance du phénomène. Il insistait sur la croissance rapide de l'activité criminelle avant qu'elle n'atteigne un sommet et ensuite, sur sa lente décroissance. Il se pourrait bien que, partout, l'allure générale de la courbe soit la même, le sommet variant selon les époques, les pays et les types de crime. Qu'est-ce qui est à l'origine du phénomène : développement puis déclin de la force physique ? Acquisition avec l'âge d'un meilleur contrôle de soi ? Difficultés d'intégration sociale des adolescents et jeunes adultes? Quoi qu'il en soit de ses causes, les effets du phénomène sont considérables. Au cours de la deuxième moitié du $\mathrm{XX}^{\mathrm{c}}$ siècle, la criminalité varie en raison directe du pourcentage d'adolescents et de jeunes adultes dans la population. L'âge est un fait à ce point important que nos législateurs opèrent une distinction radicale 
entre les systèmes de justice pour mineurs et pour adultes. Et c'est à cause des transformations majeures qui se manifestent dans l'organisme au cours de la vie que s'est imposée la nécessité d'une criminologie développementale et de sa sœur siamoise, la recherche longitudinale.

Les raisons ne manquaient donc pas de consacrer au thème de L'âge et la question criminelle, le septième colloque de l'Association internationale des criminologues de langue française, qui s'est tenu à Montréal en août 2000. Les divers aspects du phénomène ont fait l'objet de conférences plénières et de quatorze ateliers. Les présentations du colloque offraient donc une abondante moisson de textes pour un numéro thématique de la revue Criminologie.

Les cinq textes retenus se présentent comme des variations sur un même thème. Marc Ouimet et Étienne Blais s'attaquent au problème classique de l'influence de la pyramide des âges et de ses variations sur l'évolution de la criminalité au cours des quarante dernières années. Ils nous réservent des surprises : les adolescents n'ont pas une contribution aussi importante aux mouvements de la criminalité que nous le pensions.

Pierre Tremblay et Paul-Philippe Paré, dans un article au titre intriguant, nous font découvrir un phénomène très mal connu des criminologues : les délinquants ont tendance à mourir à un âge plus jeune que les non délinquants. Ce fait est en rapport avec un autre, mieux connu : la survictimisation des délinquants. La question s'impose : pourquoi les individus qui s'adonnent au crime ont-ils tendance à mourir prématurément?

Les recherches longitudinales permettent aux chercheurs de sauter par-dessus la barrière qui nous fait opposer les jeunes contrevenants et les délinquants adultes. C'est ce que fait Michel Born. Suivant l'évolution de jeunes délinquants au-delà de l'âge adulte, il identifie les caractéristiques des délinquants qui continuent de l'être une fois qu'ils sont devenus adultes.

L'article signé par Nadine Lanctôt, Mélanie Bernard et Marc Le Blanc porte sur la délinquance et la déviance des jeunes filles. Il décrit comment s'élabore la séquence des activités déviantes et délinquantes de l'enfance jusqu'au début de l'âge adulte, en passant par l'adolescence.

Finalement, Jean-Luc Bacher se propose de comparer l'âge des délinquants économiques et celui des autres catégories de délinquants. Il constate des différences nettes entre les uns et les autres et fournit le pourquoi de cet écart. 